\title{
Safety Management of Non-urban Roads in Israel: An Application of Empirical Bayes Evaluation
}

\author{
Victoria Gitelman ${ }^{1}$ and Etti Doveh ${ }^{2}$ \\ 1. Transportation Research Institute, Technion, Israel Institute of Technology, Haifa 32000, Israel \\ 2. Technion Statistical Laboratory, Technion, Israel Institute of Technology, Haifa 32000, Israel
}

\begin{abstract}
A safety management system was established to provide for continuously improved safety levels of the non-urban roads in Israel. One of the main functions of the system lies in the identification and treatment of HL (hazardous locations) on existing roads. In line with the state-of-the art in road safety, the HL identification is based on an empirical Bayes evaluation, where an HL is recognized using a high positive difference between the number of accidents expected at the site and that predicted for similar sites. The latter is estimated using safety performance functions that were developed for local conditions, including single- and dual-carriageway road sections, and various types of intersections: signalized/non-signalized, three- and four-legged. The procedure of HL identification is applied annually, serving as a basis for the working programs on road infrastructure improvements. Positive safety effects of such improvements were recently reported in the country. These activities comply with the Road Infrastructure Safety Directive that was recently introduced in the European Union.
\end{abstract}

Key words: Safety management system, non-urban roads, safety performance functions, hazardous locations.

\section{Introduction}

Road accidents on non-urban roads comprise about $60 \%$ of total fatal, $30 \%$ of total serious and $25 \%$ of total injury accidents in Israel [1]. The NTIC (National Transport Infrastructure Company) is responsible for maintenance, upgrading and expansion of the rural (non-urban) road network in Israel, which currently comprises over 4,500 km of roads. In 2007, the NTIC initiated establishing a decision-support system for managing the road system under its responsibility, which unites three systems: a pavement management system, a bridge management system and an SMS (safety management system). The NTIC stated its goal as providing for continuously improved safety levels of the road network, where the SMS was intended to support the implementation of this policy.

Broadly, the SMS should assist in two processes: (1) treatment of hazardous locations on the existing road

Corresponding author: Victoria Gitelman, Ph.D., senior research scientist, research fields: road safety, traffic engineering, evaluation studies and safety performance indicators. network; and (2) upgrading the safety level of the road system. Therefore, the main functions of the SMS lie in dealing with the identification of HL (hazardous locations) on existing roads, gaining information and knowledge on road safety treatments-infrastructure improvements for removal/reduction of safety risks, providing data and tools for conducting network analyses and monitoring road infrastructure improvements [2]. In addition, the SMS may assist in the economic evaluation and planning investments in road infrastructure improvements.

Fig. 1 presents a functional specification of the system, according to Ref. [2]. The main SMS components include: databases, safety models and supportive tools for monitoring safety improvements in a single project, conducting analyses of the safety performance of the road network and producing summary reports. In line with the specification, the SMS databases consist of:

- Road surveys-information on road infrastructure characteristics collected through periodic field surveys of the whole road network, 
including geometric characteristics, roadside conditions, signing and marking, presence of safety devices, etc. The information is available in the form of both detailed video-log data and quantitative values estimated for road units [3];

- Road accidents - numbers and characteristics of accidents produced from the annual road accidents files of the CBS (Central Bureau of Statistics);

- Traffic volumes - average annual traffic volumes on road sections and intersections, from the CBS traffic count files;

- GIS - a geographical information system's platform for data presentation;

- A knowledge-base about road infrastructure improvements including descriptions and values regarding their safety efficiency. The latter are given in terms of safety effects or accident modification factors stemming from both local studies, e.g., Ref. [4] and international experience, e.g., Ref. [5].

Presently, the SMS includes two types of models: (1) reactive models which are used for the identification of hazardous locations on the existing road network; and (2) pro-active models which may help in detecting sites with infrastructure deficiencies that increase accident risks. The reactive models fit the original Module B (Fig.1) and are applied regularly, providing a basis for building the programs of road infrastructure improvements. The pro-active models refer to the planned Module A, but are still rarely used.

The reactive or safety models of the SMS include a procedure and SPFs (safety performance functions), which were developed for the HL identification on the existing road network. A safety performance function is a multivariate model, which shows a relationship between accidents and traffic flows and (optionally) other road characteristics of the road sites [5-7] and, thus, can be used for predicting the annual accident number at a site based on its traffic volumes and road infrastructure characteristics. SPFs are usually developed for certain types of road sites, where according to the international practice of correct safety evaluations, e.g., Refs. [8, 9], they should be applied to estimate the expected number of accidents at a site, prior to the HL selection.

In this paper, we describe a procedure that serves
Database

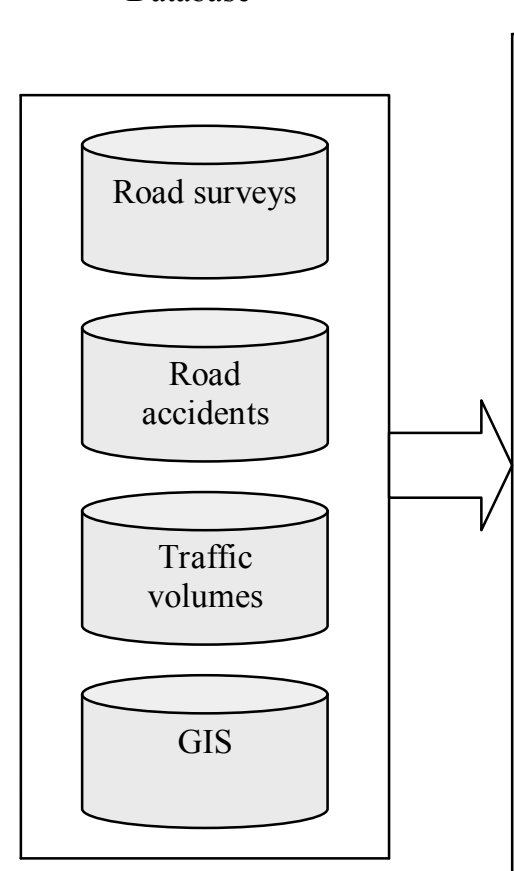

Tools

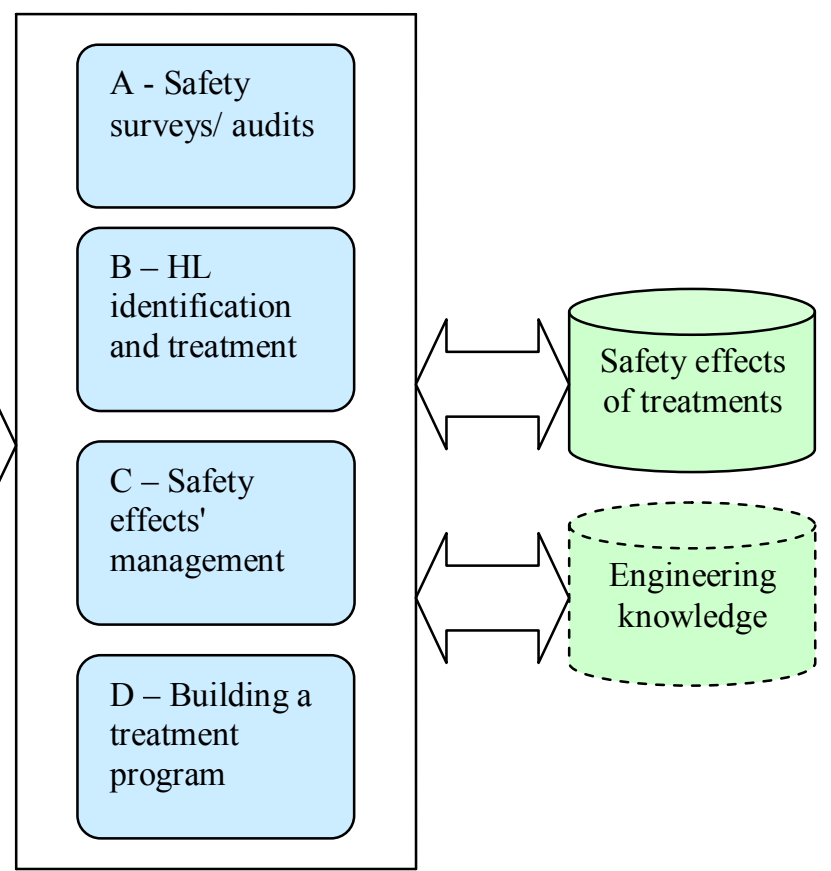

Fig. 1 Functional specification of the SMS. 
for the HL identification on the rural road network, in Israel, and present SPFs that were developed for various types of sites under local conditions. Furthermore, we discuss the experience of safety management of existing non-urban road network in Israel related to best practice recommendations.

\section{The Hazardous Locations' Identification Procedure}

Improving the safety of the road network is not based on rebuilding the entire network, but on improving parts of it. The concept of $\mathrm{HL}$ identification assumes that there are road sites-road sections and intersections, with engineering deficiencies, which do not function properly from a safety viewpoint. The exposure level at such sites, as reflected in the traffic volumes, does not explain the high accident numbers observed. Therefore, there is probably a design deficiency or inadequacy of road characteristics compared to the requirements that can be identified and improved.

The process of HL identification is intended for an initial screening of road sites, in order to focus on sites more "promising" in terms of potential benefits of intervention - the application of road engineering measures $[8,10]$. This process can be described as an examination of accident frequencies on road sites of the network, in order to point out the sites with "irregularly high" accident numbers [8]. The threshold value for such an examination (or "normal" accident numbers) is defined by a RP (reference population). The difference in safety between the site and the RP indicates the extent of the problem of a particular site or its potential for improvement. In a general case, not a simple difference between accident numbers, but a difference between the quantitative criteria is estimated as:

$$
P I_{j}=I C_{j}-I C_{r p}
$$

where, $P I_{j}$ - potential for improvement at site $j$; $I C_{j}$-value of the identification criterion at site $j$; $I C_{r p}$-value of the identification criterion of RP.
In the SMS, the HLs are defined as locations where the number of accidents is higher than that which would be expected according to their characteristics and, thus, could be treated for improvement. In the literature, various methods of HL identification can be found-see reviews in Refs. [8-11]. These methods can be classified according to the parameter applied as identification criterion in Eq. (1), such as: accident frequency, accident rate, critical accident rate, equivalent property damage only index, relative severity index, combined criteria, excess predicted accident frequency using SPF, etc. [8, 9]. To note, in the US Highway Safety Manual [9], this parameter is termed "network screening performance measure".

In line with the state-of-the-art in road safety evaluations $[6,8,9,12,13]$, the method for $\mathrm{HL}$ identification should account for such phenomena as: the random nature of accidents; the exposure level-traffic volumes at the site; regression-to-the-mean; levels of accident severity. To exclude the impacts of the confounding factors, the HL identification should rely on an empirical Bayes evaluation. By this method, the expected number of accidents at a site (or its safety level) is estimated as a weighted value of two components: (1) the mean number of accidents that are expected on such type of sites (e.g., road sections with similar layout and traffic volumes); and (2) the number of accidents observed at this site in the past. The first component should preferably be estimated using a multivariable statistical model-SPF, fitted to local conditions $[8,9,13]$.

Following Eq. (1), an $\mathrm{HL}$ is recognized using a high positive difference between the number of accidents expected at the site and that predicted for similar sites using SPF.

In addition, the form of relationship between the site's traffic exposure and road characteristics and accident occurrences may differ for various accident severities (slight, serious, fatal), where accident 
severity has obvious economic implications. For example, the manual [8] showed that in the US, the unit costs of fatal, serious and slight injury accidents were 2.6, 0.18 and 0.019 million US\$, respectively, providing a ratio of 137:9.5:1 that can be used as weighted factors for estimating equivalent slight accidents for fatal and serious accidents. Similar estimates for Israeli conditions demonstrated [14] that the unit costs of accidents on rural road sections were 6.3, 0.89 and 0.048 million NIS (New Israeli Shekels; $1 \$=4$ NIS) for fatal, serious and slight injury accidents, respectively, indicating a ratio of 131:18:1 (for rural road intersections, the ratio was 134:19:1). The typical accident cost units in Israel were received following the guidelines on the appraisal of transport projects [15], where a major difference in the costs of severe versus slight injury accidents, both in Israel and other countries, stems from the adoption of a willingness-to-pay approach for estimating fatality and serious injury costs $[16,17]$. The SMS procedure for selecting HL sites accounts for accident severities, where separate SPFs were fitted for slight, serious and fatal accidents, and the potential for improvement of a site is estimated by means of weighting the difference between the number of accidents expected at the site and that predicted for similar sites, across the three severity levels.

The SMS procedure for selecting HL sites was developed having examined the international experience and mostly following Persaud et al. [12], and Persaud [7]. The HL identification is performed separately for road sections and intersections, and includes four steps:

(1) The expected number of accidents at a site is estimated by the empirical Bayes method, i.e., by weighting the number of accidents previously observed at the site and that predicted for this site (using SPF models), where the values are obtained for the three levels of accident severity, as follows:

$$
\begin{gathered}
m_{i}=\left(w_{i} \cdot S P_{i}\right)+\left(1-w_{i}\right) \cdot X_{i} / n \\
w_{i}=k /\left[k+\left(n \cdot S P_{i}\right)\right]
\end{gathered}
$$

where, $i=1,2,3$ for slight, serious and fatal accidents, respectively; $m_{l}$ - the expected number of accidents at the site; $n$-the number of years for counting accidents at the site; $X_{l}$-the number of accidents observed at the site in $n$ years; $S P_{l}$ - the predicted number of accidents for this type of sites (using SPF); $k$-the estimate of uncertainty of the SPF models which is equal to the inverse value of the over-dispersion parameter of the negative-binomial regression model, see Persaud et al. [12];

(2) The potential for safety improvement $\left(P S I_{i}\right)$ of a particular site is estimated as the difference between the expected number of accidents at the site $\left(m_{i}\right)$ and the predicted number of accidents for this type of sites $\left(S P_{i}\right)$, where this value is obtained for the three levels of accident severity:

$$
P S I_{i}=m_{i}-S P_{i}
$$

(3) The summary value of the potential for safety improvement (Sum_PSI) of a particular site is estimated as a weighted sum of the values obtained in the previous step $\left(P S I_{i}\right)$, according to the three levels of accident severity:

$$
\text { Sum_PSI }=\sum_{i}\left(P S I_{i} \cdot \lambda_{i}\right)
$$

where, $\lambda_{l}$ - the weights based on the economic costs of typical accidents on rural roads which reflect the relation between the unit costs of fatal, serious and slight injury accidents, respectively (as explained above);

(4) Rating the sites is performed in a descending order of summary potential for safety improvement (Sum_PSI). The sites with positive values of the index demonstrate a potential for safety improvement. The higher the index value, the site is more appropriate to be an HL. Initially, a threshold of "Sum_PSI > 2" was applied for selecting HL in the SMS. This means that the number of accidents expected at the HL site is higher by two or more (weighted) accidents, per year, compared to the number of accidents predicted for this type of sites with similar traffic volumes. 


\section{Development of Safety Performance Functions}

For the SMS, SPFs were developed for single- and dual-carriageway road sections, and for various types of intersections: signalized/non-signalized, three- and four-legged. Due to the HL identification procedure's needs, for each type of sites, three models were fitted, for various accident severities. The models were developed based on accident data in three years, 2003 2005. Preparing the data, the road network was divided into short sections of $1 \mathrm{~km}$ in length, where, for each section, road type, traffic volumes and accident numbers were assigned; in total, 10,339 road sections (in three years) were considered, including 2,343 dual-carriageway and 7,996 single-carriageway sections. Similarly, data on 5,262 intersections (in three years) were collected, including the type of control, configuration, traffic volumes (on main and secondary roads) and annual accident numbers.

First, the variance-mean relationship of the accidents, for each "site type-accident type", combination was explored, to check if it fits a negative binomial model (or at least a Poisson model with over-dispersion). For this stage, we partially used the methodology suggested in Wood [18]. Typically, a quadratic relationship between variance and mean was observed in the data, supporting the selection of a negative binomial model for the SPF development. Second, we explored what transformations of traffic volume should be included in each model of accidents versus traffic volumes. At this stage, we used generalized additive models, a powerful technique developed by Hastie and Tibshirani [19], enabling to explore the form of the relationship between two variables. The exploration was done for each year separately due to a dependency of accident data among years' problem. In most cases, we found that a log-transformation of traffic volumes best suited the data. Hence, the data distributions and the forms of their relationships were verified, during the models' development, using the above techniques.
The final models were fitted for each "site type-accident type" combination, using GEE (generalized estimating equations), for handling correlations among years. The models were developed using the PROC GENMOD tools of the SAS package, while the GLIMMIX procedure of SAS was used to estimate the correlation parameters. The final model was a negative binomial regression model fitted to the observed number of accidents at each site as the dependent measure. A negative binomial model belongs to the class of generalized linear models which are an extension of traditional linear models that allows the mean of a population to depend on a linear predictor through a nonlinear link function. For sections, the independent measure was the logarithm of the traffic volume, where the logarithm of section length was used as an offset. For junctions, the independent variables were the logarithms of the main and secondary traffic volumes, where separate models were fitted to signalized and non-signalized sites. Due to non-convergence problems, the data from two intersection configurations, three- and four-legged, were modeled at the same mega-model, yet separately for sites with and without traffic lights.

For each type of sites, we modeled all three accident types (fatal, serious and slight) and all the three years simultaneously, in order to be able to estimate the correlations among the accident types and different years. For example, for sections, the linear predictor had the form:

$$
\eta_{i j k}=\beta_{0 i}+\beta_{1 i} \cdot \log \left(V_{j k}\right)+\log \left(L_{k}\right)
$$

where, $\eta_{i j k}$ is the logarithm of the predicted value of accident numbers for the $i$ accident type at section $k$ in year $j ; L_{k}$-length of section $k ; V_{j k}$-traffic volume at section $k$ in year $j ; \beta_{0 i}, \beta_{1 i}$ are parameters to be estimated. For intersections, a similar predictor was applied but without a length-parameter.

\section{Results and Discussion}

\subsection{SPFs Fitted to Local Conditions}

Tables 1 and 2 provide the models fitted to single- 
Table 1 SPF fitted to single-carriageway road sections.

\begin{tabular}{lllll}
\hline Parameter & Estimate & Standard error & Z-statistics & $p$-value \\
\hline Intercept & -9.6048 & 0.2925 & -32.84 & $<0.0001$ \\
$I \_v$ & 0.9487 & 0.0322 & 29.48 & $<0.0001$ \\
Type F & -2.2271 & 0.0687 & -32.40 & $<0.0001$ \\
Type S & -1.2616 & 0.0451 & -27.97 & $<0.0001$ \\
Type L & 0.0000 & - & - & - \\
\hline
\end{tabular}

Table 2 SPF fitted to dual-carriageway road sections.

\begin{tabular}{lllll}
\hline Parameter & Estimate & Standard error & Z-statistics & $p$-value \\
\hline Intercept & 10.4071 & 6.4379 & 1.62 & 0.1060 \\
$I \_v$ & -2.8110 & 1.2269 & -2.29 & 0.0220 \\
Type F & -2.3926 & 0.0830 & -28.82 & $<0.0001$ \\
Type S & -1.4845 & 0.0571 & -26.02 & $<0.0001$ \\
Type L & 0.0000 & 0.0000 & - & - \\
$\left(I \_v\right)^{2}$ & 0.1703 & 0.0584 & 2.92 & 0.0035 \\
\hline
\end{tabular}

l_v—logarithm of traffic volume, type-accident severity level (F: fatal, S: serious, L: slight). Dispersion parameter was estimated by maximum likelihood; it was $1.0126(0.741)$ for single-carriageway, $0.7151(0.0621)$ for dual-carriageway roads.

and dual-carriageway road sections, respectively. The interaction between traffic volumes and accident types was non-significant, meaning that the volume increase has the same multiplicative influence on all accident types. The models predict the annual number of accidents, of the three severity levels, on each type of road sections. In both models, significant impacts of traffic volumes and accident severity levels were ascertained (at 0.05 level).

Based on Table 1, the SPFs for a single-carriageway road section have the form:

$$
S P=L \cdot e^{-9.6048} \cdot V^{0.9487} \cdot e^{I}
$$

where: $L$ - the section length $(\mathrm{km}), V$-average daily traffic volume (vehicles), $e$-exponent, $I$-coefficients of accident severity: $I=-2.2271$ for fatal accidents, $I=-1.2616$ for serious accidents, $I=0$ for slight accidents; the estimate of uncertainty of this model $(k$ in Eq. (3)) is $1 / 1.0126=0.9876$.

Similarly, the SPFs for prediction of accident numbers on a dual-carriageway road section are:

$$
S P=L \cdot e^{10.4071} \cdot V^{2.8110} \cdot e^{I} V^{0.1703 \ln (V)}
$$

where: $I=-2.3926$ for fatal accidents, $I=-1.4845$ for serious accidents, $I=0$ for slight accidents; the estimate of $k$ of this model (for Eq. (3)) is 1.3984 .

Concerning intersections, six groups of SPF models were developed, depending on the type of control (with and without traffic lights), level of traffic volumes on the main roads and the availability of data on traffic volumes on secondary roads (Fig. 2). Each group of models includes SPFs for two intersection configurations (three- and four-legged) and the three levels of accident severity.

For example, the SPFs for prediction of yearly accident numbers on a non-signalized intersection, with a traffic volume on the main road below 40,000 vehicles per day and no information on traffic volumes on the secondary road (Group A in Fig. 2), are:

For three-legged intersections,

$$
S P=e^{-0.9427} \cdot(V 1 / 11,000)^{1.0706} \cdot e^{I}
$$

For four-legged intersections,

$$
S P=e^{-0.9362} \cdot(V 1 / 11,000)^{0.8171} \cdot e^{I}
$$

where, $V 1$ - average daily traffic volume on the main road (vehicles), $e$-exponent, $I$-coefficients of accident severity: $I=-3.2231$ for fatal accidents, $I=$ -2.0214 for serious accidents, $I=0$ for slight accidents. The dispersion parameter of this model was $3.446(0.239)$, providing $k=0.29$. In this model group, we used the value of $V 1 / 11,000$ instead of $V 1$ in order to give meaning to the model intercept.

Similarly, the SPFs fitted for prediction of annual accident numbers on a signalized intersection, with a 


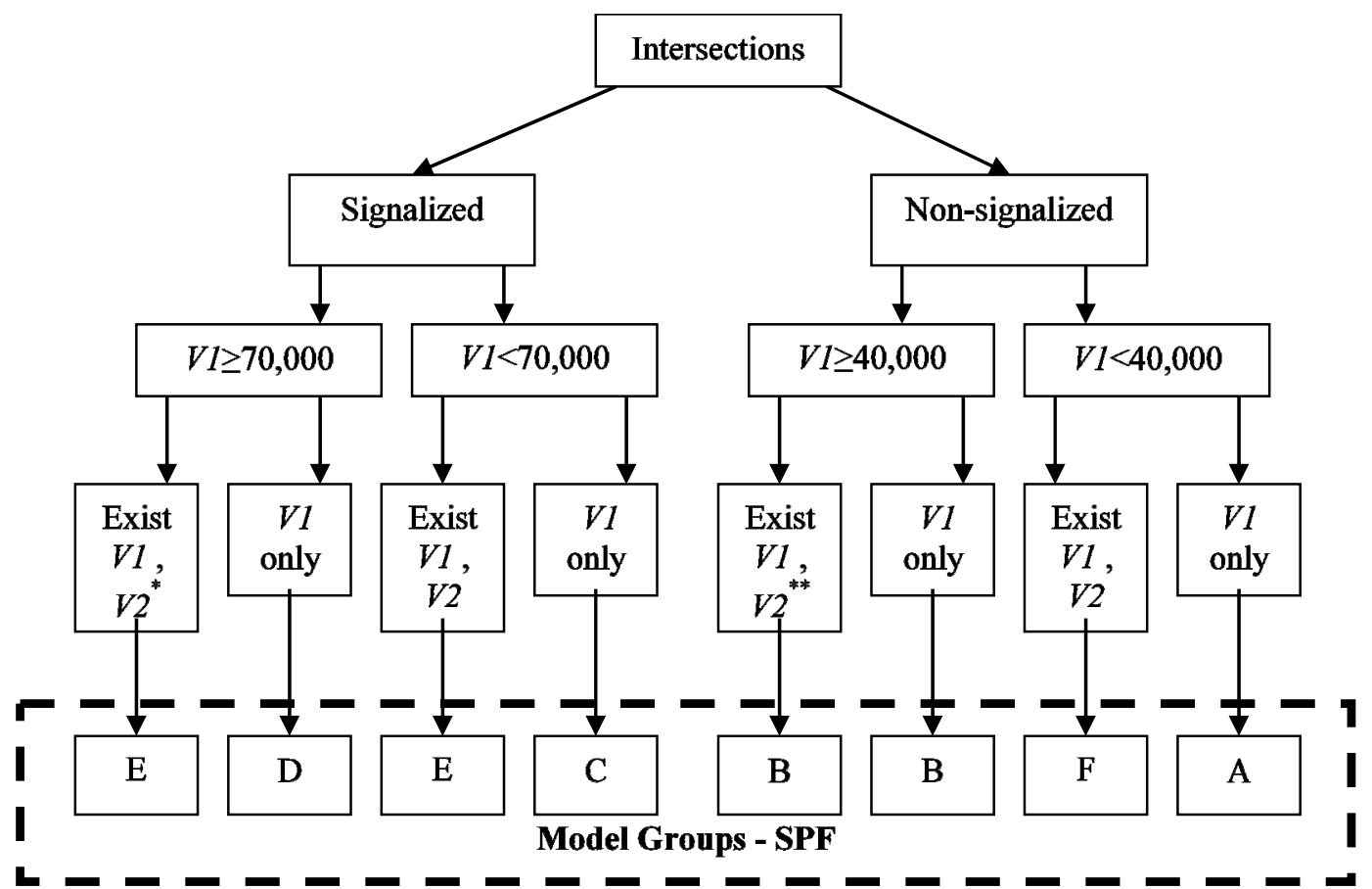

Fig. 2 Groups of SPF models fitted for prediction of accident numbers at intersections.

Notes: $V 1$ - traffic volume on the main road; $V 2$ - traffic volume on the secondary road;

*Due to scarce data, separate models were not fitted to this group of intersections;

**Lack of significance was found for $V 2$, thus Group B models are applicable.

traffic volume on the main road below 70,000 vehicles per day (Group C in Fig.2) were:

For three-legged intersections,

$S P F=e^{-16.0} \cdot(V 1)^{1.24} \cdot e^{\{-0.86 \cdot \max [0, \ln (V 1)-\ln (35,000)]\}}$

$S P \_S=e^{-7.85} \cdot(V 1)^{0.61} \cdot e^{\{-0.86 \cdot \max [0, \ln (V 1)-\ln (35,000)]\}}$

$S P_{-} L=e^{-3.27} \cdot(V 1)^{0.38} \cdot e^{\{-0.86 \cdot \max [0, \ln (V 1)-\ln (35,000)]\}}$

For four-legged intersections,

$S P_{-} F=e^{-10.80} \cdot(V 1)^{0.81} \cdot e^{\{-0.86 \cdot \max [0, \ln (V 1)-\ln (35,000)]\}}$

$S P S=e^{-10.56} \cdot(V 1)^{0.91} \cdot e^{\{-0.86 \cdot \max [0, \ln (V 1)-\ln (35,000)]\}}$

$S P_{-} L=e^{-11.44} \cdot(V 1)^{1.21} \cdot e^{\{-0.86 \cdot \max [0, \ln (V 1)-\ln (35,000)]\}}$

where, $S P_{-} F, S P_{-} S, S P_{-} L$ mean fatal, serious and slight accidents, respectively. The dispersion parameter of this model was 1.011 (0.078), providing $k=0.99$. The details of other SPF models for Israeli rural intersections are given in Refs. [2, 14].

Fig. 3 provides a visual presentation of the relationship between the daily traffic volume and predicted accident numbers on single- and dual-carriageway road sections (of $1 \mathrm{~km}$ in length), based on the SPFs (Eqs. (7) and (8)). The models for both road types indicate a direct relation between an increase in traffic volume and accident increase. For any level of traffic volume and both road types, the expectancy of serious accidents is lower than that of slight accidents and the expectancy of fatal accidents is lower than that of serious ones. For any level of exposure, more accidents are expected for a single-carriageway road section than for a dual-carriageway one, where this result is consistent for all severity levels. These findings for local conditions are in line with the international knowledge on the subject $[5,8,9]$.

Fig. 4 illustrates the numbers of accidents predicted for signalized intersections, both three- and four-legged, by various severity levels (based on Eqs. (11) and (12)). The SPF models for intersections demonstrated that, in general, for higher traffic volumes more accidents are expected, across various severity levels. However, the models for signalized intersections showed a significant change in the volume-accident relationship around " 35,000 " value of the average daily traffic volume, where for higher 


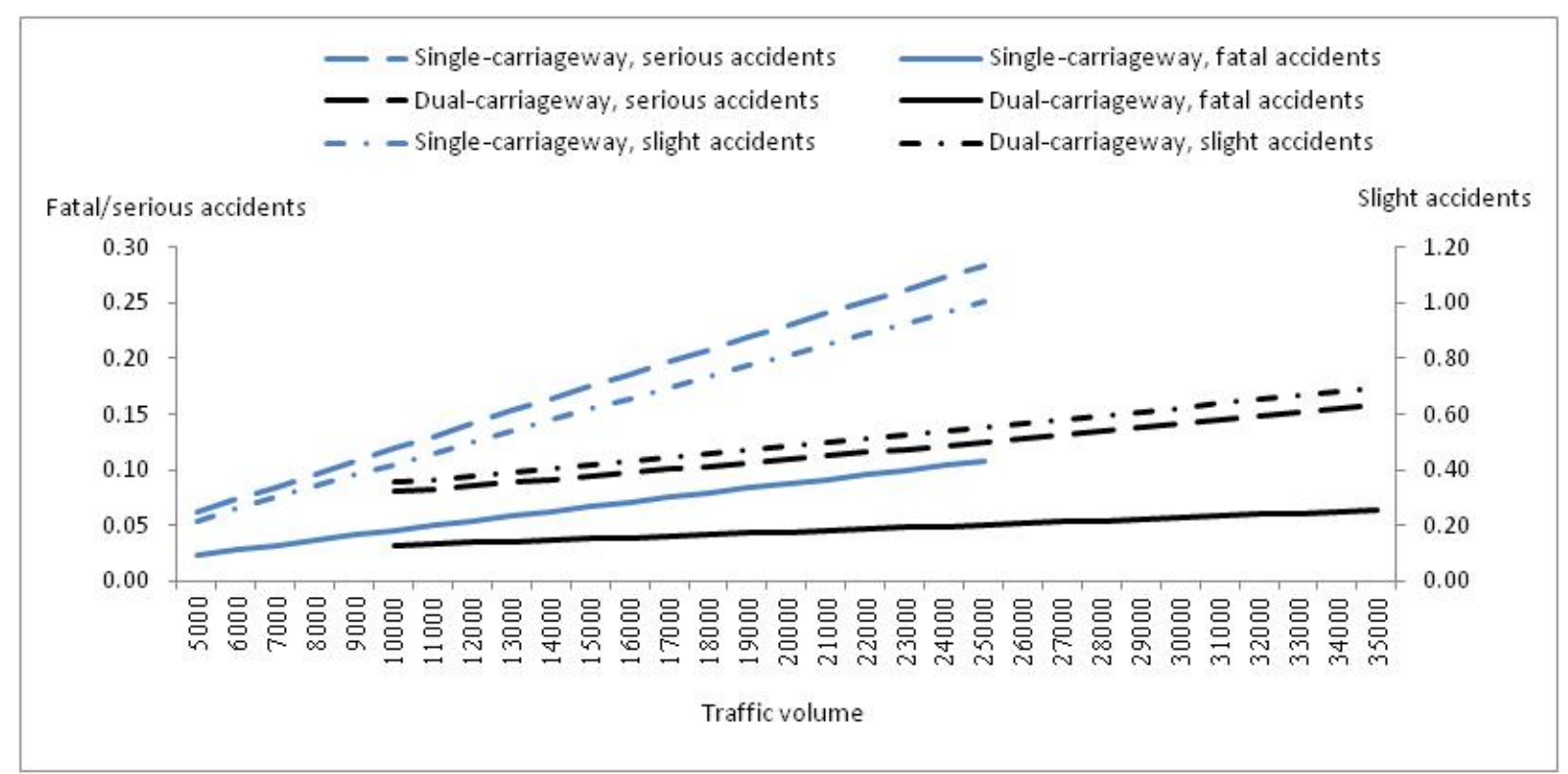

Fig. 3 Accident numbers predicted for single- and dual-carriageway road sections, by accident severity level.

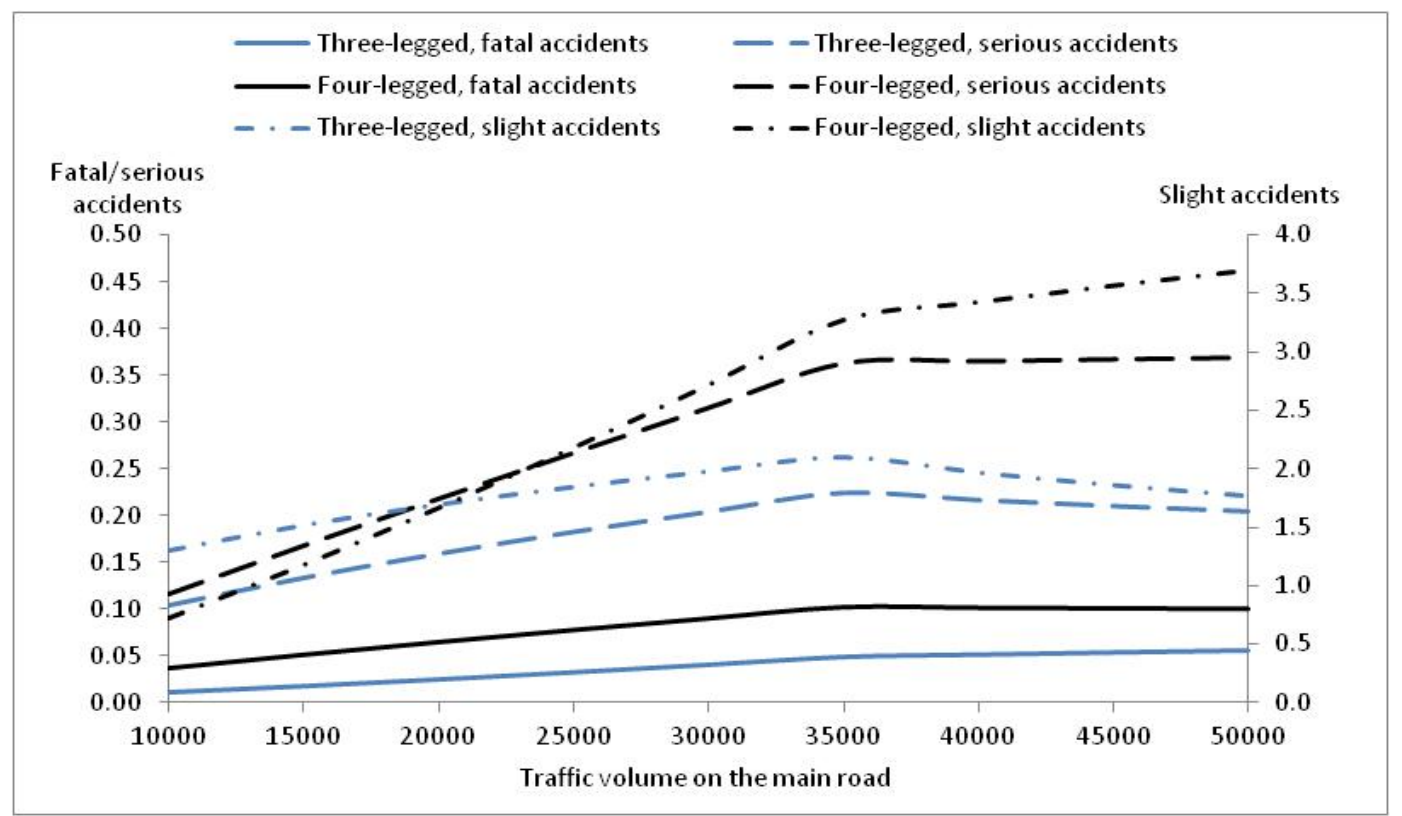

Fig. 4 Accident numbers predicted for signalized intersections, by junction configuration and accident severity.

traffic volumes (over 35,000 vehicles per day) an increase in accidents following the increase in traffic is moderated related to lower traffic volumes, or even a slight decrease in some accident numbers is observed following an increase in traffic volume. Such a "breaking point" in the exposure-accident relationship is not common in the international literature where usually a monotonous traffic-accident link is reported $[8,9,20]$. However, this change was recognized during preliminary data analyses, found significant in the models fitted and, therefore, was kept for further application in the SMS. Our experience shows that the form of exposure-accident relationship may change in various ranges of the traffic volumes.

Fig. 4 indicates that, in general, under similar traffic volumes, more accidents are expected at the four-legged than those at the three-legged signalized 
junctions, for various accident severity levels; similar relations were reported abroad, e.g., in Ref. [20]. In the local findings, a small exception can be seen under low traffic volumes, below 20,000 vehicles per day, where the three-legged signalized intersections are associated with higher numbers of slight accidents than the four-legged.

As evident, various forms of volume-accident relationships can be explored using the SPF models fitted for the local conditions.

\subsection{The SMS Functioning Using the Tools Developed}

Following the SPF models' development for the SMS, the Bayesian procedure of HL identification was applied annually, serving as a basis for the preparation of a working program on infrastructure improvements of existing roads. The first application of the screening tools, in 2007, produced a list of $337 \mathrm{~km}$ of road sections and 125 intersections that suited the HL definition [14]. In consequent years, the HL list was reproduced, based on the last three-year accident data. The SMS output is usually ranked according to the Sum_PSI values and serves as a basis for selecting the most problematic sites from the top of the HL list by using additional criteria. Then, the sites are examined by traffic engineers to suggest road infrastructure improvements that could eliminate similar accidents in the future. The selection of treatments is based on the list of measures associated with proven accident-reduction effects, according to the available experience $[4,5]$. The HL sites are also compared with the lists of sites that were treated recently and with those included in the long-term plans of upgrading existing roads, to exclude a redundancy. Finally, an annual HL treatment program is composed, which typically comprises about 60 sites.

The SMS evaluation tools stimulated systematic work on the HL identification and treatment on the rural road network of the country. Local evaluation studies demonstrated positive safety effects of such road infrastructure improvements on road safety. For example, Gitelman et al. [4] reported that 19 types of road infrastructure improvements applied over the years 2007 2009, were associated with significant accident reduction factors and that the HL treatment project provided an average annual saving of 224 injury accidents. Among commonly applied treatments were: safety barrier improvements on roadsides, shoulder treatments, upgrading a single-carriageway to a dual-carriageway road section, building a roundabout, traffic lights' installation at a junction. In general, the national data demonstrate [1] that recently, a remarkable decrease in accident numbers on the non-urban road network was observed, where for example in 2011 2012 compared to 2005 2006, the number of fatal and slight accidents declined by over $20 \%$, the number of serious accidents - by over $40 \%$. These reductions relate, at least partially, to road infrastructure improvements.

In many countries, HL or black-spots' detection and treatment is considered as an important management tool for improving the safety level of the existing road network [9, 11, 13, 21]. The European Union recently promoted a Road Infrastructure Safety Directive that requires road authorities to apply several tools for improving the safety level of national road infrastructure, one of which is the identification and management of HL sites [22]. The SMS function in Israel actually complies with the European directive. Moreover, the HL identification procedure that was adopted by the SMS is based on the empirical Bayes evaluation, enabling to exclude the impacts of such confounding factors as exposure, infrastructure characteristics and regression-to-the-mean. Such an approach is the most advocated today in road safety research $[8,9,23,24]$, whereas it is not common yet in international practice. Many research studies demonstrated examples of using the empirical Bayes approach for black-spot identification on various road networks [12, 23-26]. However, a systematic application of such an approach on the national road 
network is not frequent. A literature survey undertaken by Sorensen and Elvik [27] showed that some components of empirical Bayes evaluation were found in the HL identification methods of such countries as Finland, Portugal, Norway and the USA. In this sense, the SMS introduced in Israel was one of the first systems which adopted the empirical Bayes method for identification of hazardous locations on the national (non-urban) road network.

\section{Conclusions}

A safety management system for the non-urban roads was established in Israel providing a basis for the continuous improvement of the safety level of the road network. The SMS procedure that serves for the identification of hazardous locations on the road network is based on the empirical Bayes evaluation, where for the needs of estimation, safety performance functions were developed for various types of road sections and intersections under local conditions. The application of an empirical Bayes evaluation for the HL identification is recommended by the state-of-the-art of road safety research, however, it is not common yet in the actual practice of the road authorities. The experience of establishing the SMS in Israel demonstrates the efforts needed for adopting an empirical Bayes evaluation on a national scale. In addition, a systematic application of the HL identification procedure in the country stimulated the working programs on road infrastructure improvements of the road network, with proven safety effects.

The current SMS functions comply with the recommendations of the European directive on road infrastructure safety management. Further development of the system can be seen in an increase of pro-active activities, i.e., promoting tools that enable the identification of sites with higher potential for accident occurrences, due to infrastructure deficiencies or improper road design characteristics. Such tools may include various forms of safety inspections of existing roads and safety audits of new road designs as recommended by the European directive [22].

\section{Acknowledgments}

Appreciation is extended to the National Transport Infrastructure Company of Israel which commissioned this research.

\section{References}

[1] CBS (Central Bureau of Statistics). 2014. Road Accidents with Casualties-Table Generator. Israel: CBS. Accessed October 6, 2015. http://www.cbs.gov.il/reader /transport/accidents.html

[2] The National Roads Company, and ARAM Engineers. 2007. Safety Management System. Version 1.4. Israel Roads Company and ARAM Engineers.

[3] MNM Engineers Company. 2013. A Guide for the Performance of Survey of Road Marking and Road Safety Features. Israel: MNM Engineers Company.

[4] Gitelman, V., Carmel, R., and Pesahov, F. 2014. "The Evaluation of Safety Efficiency of Non-urban Infrastructure Improvements: A Case Study." European Transport Research Review 6: 477-91.

[5] Elvik, R., Hoya, A., Vaa, T., and Sorensen, M. 2009. The Handbook of Road Safety Measures. 2nd ed. Bingley, UK: Emerald Group Publishing.

[6] Hauer, E. 1997. Observational Before-After Studies in Road Safety. Oxford: Pergamon Press.

[7] Persaud, B. 2001. "Statistical Methods in Highway Safety Analysis: A Synthesis of Highway Practice." NCHRP (National Cooperative Highway Research Program) Synthesis 295, Transportation Research Board, Washington, D.C.

[8] PIARC (Recommendations from World Road Association). 2003. Road Safety Manual. World Roads Association.

[9] AASHTO (American Association of State Highway and Transportation Officials). 2010. HSM (Highway Safety Manual). 2010. Washington, D.C.: AASHTO.

[10] Hauer, E. 1996. "Identification of Sites with Promise." Transportation Research Record 1542: 54-60.

[11] Geurts, K., and Wets, G. 2003. Black Spot Analysis Methods: Literature Review. Belgium: Limburgs Universitair Centrum.

[12] Persaud, B., Lyon, G., and Nguyen, T. 1999. "Empirical Bayes Procedure for Ranking Sites for Safety Investigation by Potential for Safety Improvement." Transportation Research Record 1665: 7-12. 
[13] Bahar, G., Masliah, M., Mollett, C., and Persaud, B. 2003. Integrated Safety Management Process. NCHRP Report 501, Transportation Research Board Washington, D.C.

[14] Gitelman, V., Doveh, E., and Hakkert, A. S. 2008. Development of Safety Management System. Report No. 311/2008, Transportation Research Institute, Technion, Haifa, Israel.

[15] Ministry of Transport and Ministry of Finance. 2006. Guidelines on Feasibility Assessment of Transport Projects. Jerusalem, Israel: Ministry of Transport and Ministry of Finance.

[16] Alfaro, J.-L., Chapuis, M., and Fabre, F. 1994. Socio-economic Cost of Road Accidents. Brussels: Commission of the European Community.

[17] European Commission. 2006. Proposal for Harmonized Guidelines. Deliverable 5 of the EU project HEATCO, European Commission, Brussels.

[18] Wood, G. R. 2002. "Generalized Linear Accident Models and Goodness of Fit Testing." Accident Analysis and Prevention 34: 417-27.

[19] Hastie, T., and Tibshirani, R. 1999. Generalized Additive Models. Boca Ranton, FL: Chapman and Hall/CRC.

[20] Bonneson, J. A., and Pratt, M. P. 2009. Roadway Safety Design Workbook. Report No. FHWA/TX-09/0-4703-P2.

[21] Persia, L., Usami, D. S., De Simone, F., Feypell De La Beaumelle, V., et al. 2016. "Management of Road
Infrastructure Safety." In Proceedings of 6th Transport Research Arena, Paper\#10863.

[22] European Union. 2008. Directive 2008/96/EC of the European Parliament and of the Council of 19 November 2008 on Road Infrastructure Safety Management. Official Journal of the European Union L 319/59-67.

[23] Elvik, R. 2008. "Comparative Analysis of Techniques for Identifying Locations of Hazardous Roads." Transportation Research Record 2083: 72-5.

[24] Montella, A. 2010. "A Comparative Analysis of Hotspot Identification Methods." Accident Analysis and Prevention 42 (2010): 571-81.

[25] Ambros, J., Havranek, P., Valentova, V., Krivankova, S., and Striegler, R. 2016. "Identification of Hazardous Locations in Regional Road Network-Comparison of Reactive and Proactive Approaches." In Proceedings of 6th Transport Research Arena, Paper\#10536.

[26] Sacchi, E., Sayed, T., and El-Basyouny, K. 2015. "Multivariate Full-Bayesian Hotspot Identification and Ranking: A New Technique." In Proceedings of 94th Annual Meeting of the Transportation Research Board, Paper\#15-0159.

[27] Sorensen, M., and Elvik, R. 2008. Black Spot Management and Safety Analysis of Road Network-Best Practice Guidelines and Implementation Steps. RiPCORD-iSEREST Project Deliverable D6. 